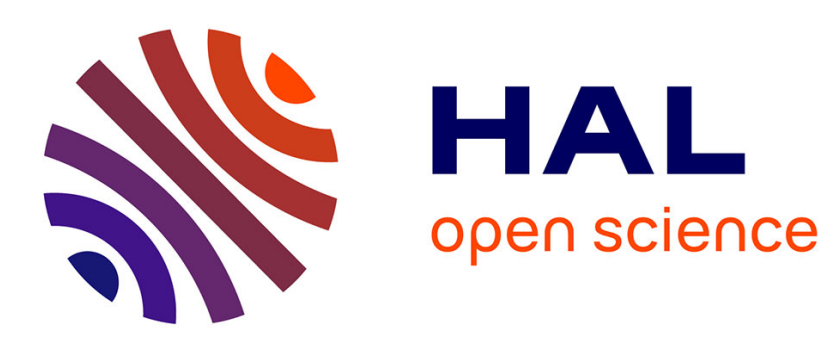

\title{
Consequences of thermo- and photo-oxidation on end-use properties of pure $\mathrm{PE}$
}

Jonathan Tireau, Laetitia van Schoors, Karim Benzarti, Xavier Colin

\section{To cite this version:}

Jonathan Tireau, Laetitia van Schoors, Karim Benzarti, Xavier Colin. Consequences of thermo- and photo-oxidation on end-use properties of pure PE. AIP Conference Proceedings, 2010, 1255, pp 101103. hal-00587903

\section{HAL Id: hal-00587903 https://hal.science/hal-00587903}

Submitted on 21 Apr 2011

HAL is a multi-disciplinary open access archive for the deposit and dissemination of scientific research documents, whether they are published or not. The documents may come from teaching and research institutions in France or abroad, or from public or private research centers.
L'archive ouverte pluridisciplinaire HAL, est destinée au dépôt et à la diffusion de documents scientifiques de niveau recherche, publiés ou non, émanant des établissements d'enseignement et de recherche français ou étrangers, des laboratoires publics ou privés. 


\title{
Consequences of thermo- and photo-oxidation on end-use properties of pure $\mathbf{P E}$
}

\author{
Jonathan Tireau ${ }^{\mathrm{a}, \mathrm{b}}$, Laetitia Van Schoors ${ }^{\mathrm{a}}$, Karim Benzarti $^{\mathrm{a}}$, Xavier Colin $^{\mathrm{b}}$ \\ ${ }^{a}$ Université Paris-Est, LCPC, Division PCM, 58, Boulevard Lefebvre, 75732 Paris cedex 15, France \\ ${ }^{b}$ PIMM (UMR CNRS 8006), Arts et Métiers ParisTech, 151, Boulevard de l'hôpital, 75013 Paris,
}

France

\begin{abstract}
Thin films of polyethylene have been exposed to thermal and photochemical accelerated agings at different temperatures and different UV intensities. In both cases, mechanical tests performed on aged samples revealed a severe embrittlement of the PE material. However, a multi-scale analysis showed that i) under thermal oxidative conditions, such embrittlement mainly resulted from a reduction of molecular mobility of the amorphous phase due to annealing phenomena, while ii) it was rather associated to a competition between chain scission and cross-linking processes under photo-oxidative conditions. As regards the oxidation mechanisms, it was found that thermo-oxidation is clearly initiated by a bimolecular decomposition of hydroperoxides, while photo-oxidation seems rather initiated by the photolysis of ketones and hydroperoxides. Over a critical threshold of the hydroperoxide concentration, thermolysis of hydroperoxides seems to predominate and even to control the overall photo-oxidation kinetics.
\end{abstract}

Keywords: Polyethylene, thermo-oxidation, photo-oxidation, embrittlement.

PACS: $82.35 .-\mathrm{x}$

\section{INTRODUCTION}

Polyethylene (PE) is commonly used in many civil engineering applications (geomembranes, protective sheaths of cable stayed bridges, gas and water pipes...) because of its low cost, easy processability, good impermeability and chemical resistance. However, in external environment, several factors such as ultraviolet radiations, seasonal temperature variations or washing by rain water can lead ultimately to a deterioration of the $\mathrm{PE}$ material ${ }^{1}$. It is usually admitted that photo-oxidation is the main cause of degradation for $\mathrm{PE}^{2}$. Nevertheless, other physical and chemical phenomena, such as physical loss and chemical consumption of antioxidants $\mathrm{s}^{3,4}$, thermo-oxidation $^{5}$ or annealing phenomena ${ }^{6}$ can also contribute to an overall degradation of the material properties.

The objective of this study was to investigate the respective effects of these various phenomena on the durability of pure PE. With this intention, thin PE films (200-300 $\mu \mathrm{m}$ thick) were exposed to two types of ageing conditions: thermal ageing in a ventilated oven at different temperatures $\left(40,60,90,100\right.$ and $\left.110^{\circ} \mathrm{C}\right)$ and photochemical ageing in a UV chamber at different intensities $\left(0.51 \mathrm{~W} \cdot \mathrm{m}^{-2} ; 0.65 \mathrm{~W} . \mathrm{m}^{-2}\right.$ and $\left.0.75 \mathrm{~W} . \mathrm{m}^{-2}\right)$ at $38^{\circ} \mathrm{C}$. Exposed samples were then characterized using a multi-scale approach: i) infrared spectrometry (IR) at the molecular level, ii) rheology in the melt state and dynamic mechanical analysis (DMA) at the macromolecular level, iii) differential scanning calorimetry (DSC), X-ray diffraction (XRD) and density measurements at the microstructural level and iv) tensile tests at the macroscopic scale. 


\section{RESULTS AND DISCUSSION}

The main results obtained for exposed specimens are presented and discussed in this section.

At the molecular scale, IR spectroscopic analysis coupled with chemical derivatization $\left(\mathrm{NH}_{3}\right.$ treatment) made it possible to identify and quantify the different oxidation products (Figure 1). As regards thermo-oxidation, the initiation stage consisted mainly in the bimolecular decomposition of hydroperoxides. Differently, for photooxidation, photolysis of hydroperoxides and ketones (by Norrish II) were identified as the main initiation reactions. Beyond a critical threshold of the hydroperoxide concentration, thermolysis of hydroperoxides seemed to predominate over the two other initiation reactions and even to control the overall kinetics of oxidation.
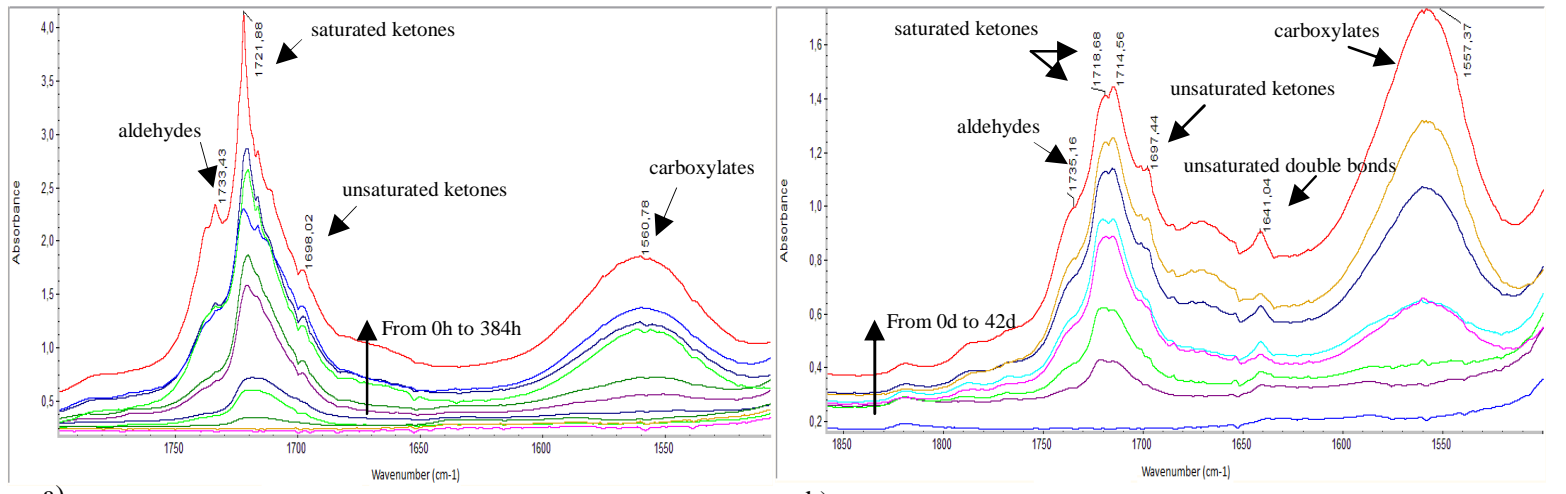

b)

FIGURE 1. Changes in the absorbance spectra after $\mathrm{NH}_{3}$ treatment on films of pure $\mathrm{PE}(200 \mu \mathrm{m})$ exposed a) in a ventilated oven at $100^{\circ} \mathrm{C}$ for periods up to $384 \mathrm{~h}, \mathrm{~b}$ ) in a Weather-o-meter chamber at $0.75 \mathrm{~W} . \mathrm{m}^{-2}$ and $38^{\circ} \mathrm{C}$ in atmospheric air for periods up to 42 days.

At the macromolecular scale, in the case of thermo-oxidation, a large part of the carbonyl species resulted from the $\beta$-scission of alkoxyl radicals. Chain scissions (s) lead to a sharp decrease in the weight average molecular mass (Figure 2a). As regards photo-oxidation, rheology in the melt state revealed, on the one hand, the occurrence of chains scissions (s) probably due to the photolysis of hydroperoxides and ketones, and on the other hand, the appearance of a cross-linking phenomenon (x) from the early period of exposure (Figure $2 b$ ).
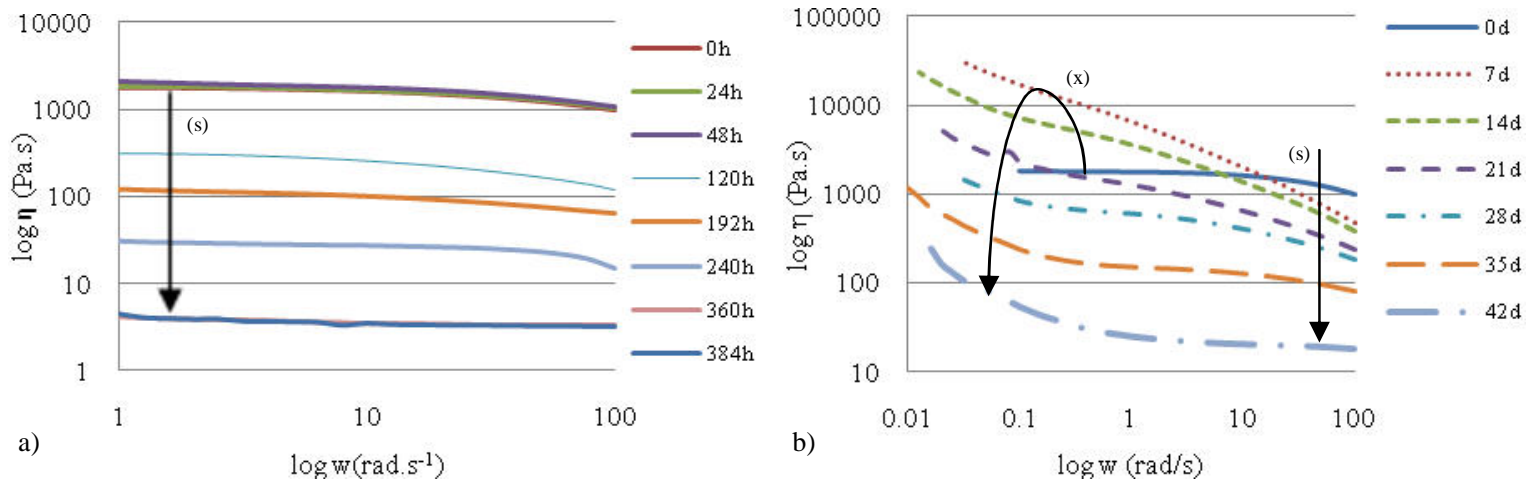

FIGURE 2. Evolutions of the rheological behaviours for pure PE films $(200 \mu \mathrm{m})$ aged a) in a ventilated oven at $100^{\circ} \mathrm{C}$, b) in a Weather-o-meter chamber at $0.75 \mathrm{~W} \cdot \mathrm{m}^{-2}$ and $38^{\circ} \mathrm{C}$ in atmospheric air.

At the microstructural scale, DSC analysis revealed microstructural changes due to annealing phenomena during the first moments of the thermo-oxidative treatment. Due to an increase in the molecular mobility, the smaller crystalline lamellae (lc) seemed to coalesce, hence forming thicker lamellae exhibiting a melting temperature higher than the ageing temperature (Figure 3a). Thus, annealing could lead to a more uniform crystalline structure in PE. After the oxidation induction time, chain scissions destroyed the entanglement 
network located in the rubbery amorphous phase and thus liberated small macromolecular segments. These segments were able to diffuse toward interfaces between amorphous and crystalline regions, leading to a global increase in the lamellae thickness $(\mathrm{Lc})$ and crystallinity ratio ${ }^{7}$. Such effects were even more pronounced in the case of photo-oxidation due to chimicrystallisation phenomena (Figure 3b).
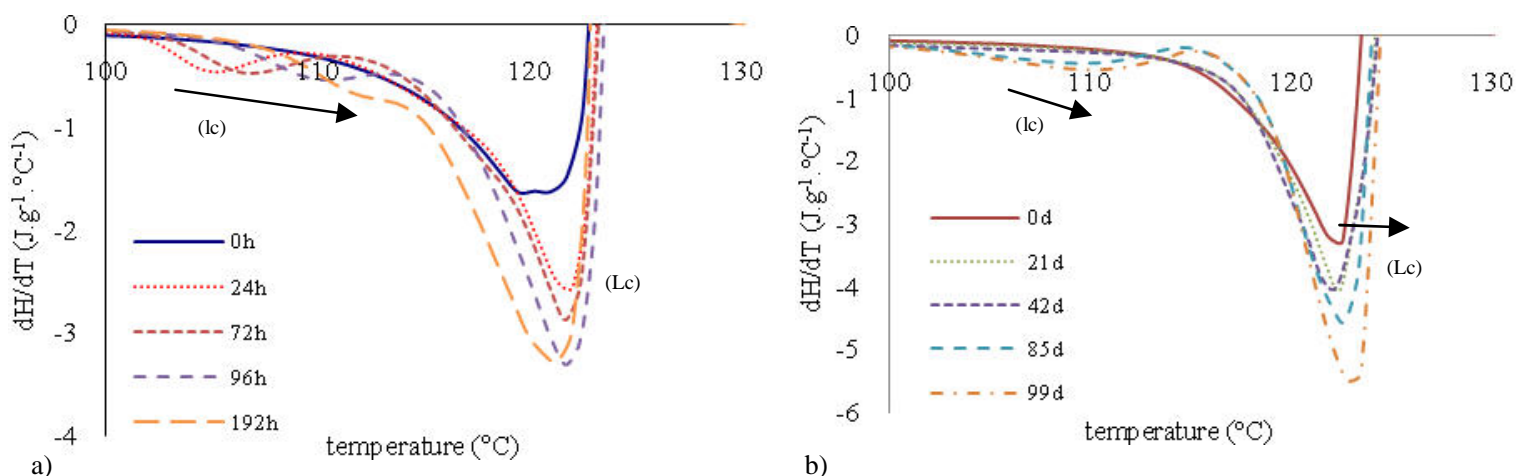

FIGURE 3. DSC derivative-thermograms for samples aged a) in a ventilated oven at $100^{\circ} \mathrm{C}, \mathrm{b}$ ) in Weather-o-meter chamber at $0.75 \mathrm{~W} . \mathrm{m}^{-2}$ and $38^{\circ} \mathrm{C}$ in atmospheric air (heating rate of $10^{\circ} \mathrm{C} / \mathrm{min}$ ).

At a macroscopic scale, ultimate tensile elongation of PE decreased sharply during thermal ageing (Figure 4a). Embrittlement appeared before the oxidation induction time, hence before the onset of chain scission. Thus, embrittlement might result mainly from a reduction of molecular mobility of the amorphous phase, which is itself a consequence of the increasing crystalline ratio. Differently, for photochemical ageing, mechanical properties of PE seemed directly affected by changes in the weight average molecular mass. A competition between chain scission and cross-linking processes led rapidly to the embrittlement of the material (Figure $4 \mathrm{~b}$ ).
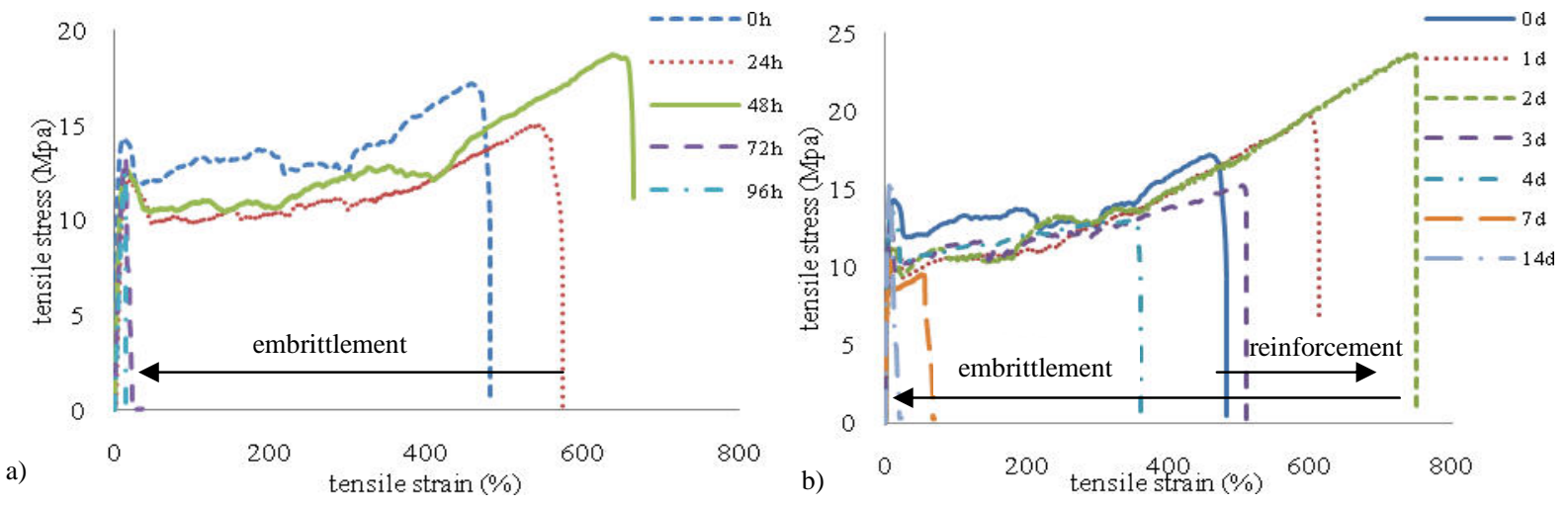

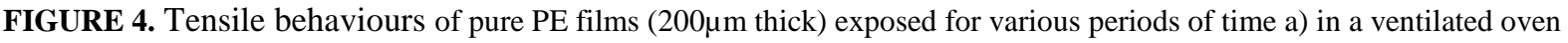
at $100^{\circ} \mathrm{C}, \mathrm{b}$ ) in Weather-o-meter chamber at $0.75 \mathrm{~W} \cdot \mathrm{m}^{-2}$ and $38^{\circ} \mathrm{C}$ in atmospheric air.

\section{REFERENCES}

1. S. Halim Hamid and I. Hussain, "Lifetime Prediction of Plastics", Handbook of Polymer Degradation, Second Edition, Revised and Expanded, New York, Marcel Dekker, 2000, pp. 669-726

2. P. Gijsman, "The long term stability of polyolefins", wibro dissertatiedrukkerij, Helmond, 1994

3. X. Colin, L. Audouin, J. Verdu, M. Rozental-Evesque, B. Rabaud, F. Martin, F. Bourgine, Polym Eng Sci 49, 1642-1652 (2009)

4. X. Colin, L. Audouin, J. Verdu, M. Rozental-Evesque, B. Rabaud, F. Martin, F. Bourgine, Polym Eng Sci 49, 1429-1437 (2009)

5. F. Delor, G. Teissedre, M. Baba, J. Lacoste, Polym Degrad Stab 60, 321-331 (1998)

6. S. Castagnet and Y. Deburck, Mater Sci Eng A 448, 56-66, (2007)

7. Gedde U.W. et Ifwarson M., Polym Eng Sci 30, 202-210 (1990) 